\title{
Annual Report on the Journal Munibe Antropologia-Arkeologia 2021
}

No changes have been made to the way the journal is edited in 2021; although the previous changes which came into effect in 2020 have been applied. The maximum number of words per paper is 7,500 (which excludes the long summary in English) and the maximum number of figures is six, apart from justified exceptions which will be considered by the Editorial Committee on an individual basis. Text and figures, videos or complementary information that do not enter in the paper can be made available via on-line links (Supplementary Information). In this way, the number of pages taken up by each paper is reduced and more studies can be published in the journal.

Twenty-seven original manuscripts were submitted to the journal in the course of 2021 and added to three that could not be assessed in 2020. Three of these manuscripts could not be reviewed in time, and these will be assessed in 2022. Therefore, a total of twenty-seven manuscripts were considered for this paper edition. Except for the two reviews published in this issue (and which will not be included in the calculations), each manuscript was assessed by at least two external reviewers, adding a third opinion in some cases or, alternatively, that of the guest editor of the manuscript. Nine manuscripts were rejected for diverse reasons. The remaining sixteen papers published here can be divided into those that needed a profound revision (seven) and the ones for which minor changes sufficed (eight), while one was accepted in its original state. Therefore, out of 25 manuscripts that were reviewed fully, the rejection index this year was $36 \%$, a little over a third.

The average time between receiving the acknowledgement of receipt signed by the corresponding author and the final decision whether to publish the paper or not was 19 weeks this year, which has again been exceptional because of the COVID-19 pandemic. This period varied greatly depending on several factors, such as the length and topic of the paper. Except in cases where the manuscript dealt with a topic that was not aligned with the usual areas of the journal, the rejections were accompanied by the negative reports of the reviewers and the opinion of the guest editor. The authors tended to take issue with those reports.

The reviewing system was once again the double blind method, in which neither the authors know the identity of the reviewers nor these know who wrote the manuscripts they are

Citations to the Munibe AA journal in different academic media per year. assessing. This meant that each manuscript had to be edited to remove any indication of the author(s) to the reviewers: references to the authors, citations in the text (replaced by the term "self-citation", to avoid breaking the thread of the argument), acknowledgements and bibliography cited. All the agents (guest editors, external reviewers and authors) were fully informed in writing about the reviewing mechanisms that would be applied and were given precise instructions about each step in the process, including a template to guide the reviewers' reports. Communications between all the agents has been carried out electronically, although each author signed an acknowledgement of receipt for their manuscript, with the date given at the head of each paper, accepting the protocol described above.

The addition of DOI codes to the papers is improving their visibility in Internet substantially, as can be seen in the records monitoring them in Google Scholar. From 1991 until the time this report was written (29th December 2020), the papers published in Munibe Antropologia-Arkeologia since 1983 have been cited 6,931 times (compared with 6,078 times, up to last year). 2,401 of these citations have been made in the last six years (contrasting with 2,323 a year ago). The papers published in the period 2016-2020 (94 papers) have already been cited 310 times, which provides an impact factor for the journal in the last five years (excluding 2021) of 3.3 citations per published paper. Taken year by year, the papers published in 2016 accumulate 128 citations; in 2017, 75 citations; in 2018, 73 citations; in 2019, 25 citations; and those in 2020, only nine times. Any author can verify in Google Scholar the number of times that their paper has been referenced and the context of the citation.

In this same period, the most often cited paper (21 times) was published in 2016 by A. Soto, A. Alday, X. Mangado and L. Montes: "Epipaleolithic and Mesolithic on the southern slopes of the Pyrenees from the lithic industry perspective". In the whole period in which citations have been counted (1983-2020), F. Etxeberria's paper published in 1994: "Macroscopic aspects of the bone subjected to fire. Revision of cremations described in the Basque Country from Archeology", cited 101 times, has accumulated the largest number of external citations.

Alvaro Arrizabalaga. Chief Editor

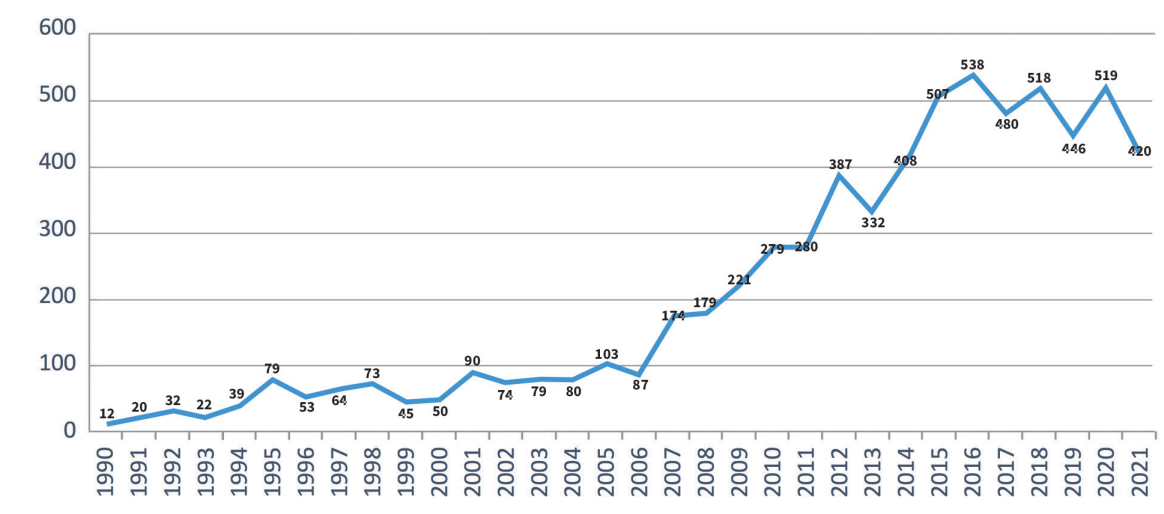




\section{Munibe Antropologia-Arkeologia 2021 aldizkariaren kronika}

2021. urtean zehar ez dugu aldaketarik egin aldizkariaren argitalpen-prozesuan, baina aurrez egindako aldaketak mantendu ditugu, 2020rako indarrean zeudenak: artikulu bakoitzeko gehieneko hitz kopurua 7.500 hitzekoa da (dena den, kopuru horretatik kanpo utzi dugu ingelesezko laburpen hedatua) eta testu bakoitzak 6 irudi izan ditzake gehienez, arrazoitutako salbuespenetan izan ezik; Argitalpen Batzordeak baloratuko ditu salbuespen horiek, banaka. Luzera horretan sartzen ez diren testuak, irudiak, bideoak edo informazio osagarria lineako esteketara bidera daitezke (Suplementary Information), hala, artikulu bakoitzaren orrialde kopurua murriztu eta jatorrizko artikulu gehiagorentzako lekua izateko.

2021ean hogeita zazpi jatorrizko artikulu jaso ditugu aldizkariaren erredakzioan, aintzat hartzeko. Horiei, 2020an baloratu ez ziren hiru artikuluak gehitu behar zaizkie. Ez dugu astirik izan hiru jatorrizko artikulu ebaluatzeko, eta 2022an zehar baloratzeko geratuko dira. Hortaz, aurten, guztira, hogeita zazpi idatzi baloratu ditugu papereko ale honetarako. Ale honetan txertatutako bi aipamenen kasuan salbu (horiek ez ditugu kopuru osoaren barnean sartuko), jatorrizko artikuluetako bakoitzak, gutxienez, kanpoko bi berrikusketa jaso ditu. Gainera, kasu batzuetan, hirugarren iritzi bat ere izan da, edo, horren ordez, artikuluaren editore gonbidatuarena. Horietako bederatzi baztertuta gelditu dira, zenbait arrazoi direla-eta. Ale honetan argitaratutako gainerako hamasei artikuluetatik zazpik aldaketa handiak behar izan dituzte eta zortzik, berriz, nahikoa izan dute aldaketa txikiekin; horiez gain, artikulu bat jatorrizko egoeran onartu da. Funtsean, hogeita bost artikuluri egin zaie ebaluazio osoa aurten, eta baztertu direnen indizea \% 36koa izan da, herena baino zerbait gehiago.

Korrespondentziaren egileak sinatutako hartu-agiria jasotzearen eta artikulua argitaratzeko edo ez argitaratzeko erabakiaren arteko batez besteko epea hemeretzi astekoa izan da aurten, COVID-19aren ondorioz berriz ere aparteko egoera izan dugun honetan. Dena den, epe hori oso aldakorra izaten da artikuluaren luzeraren edo gaiaren moduko faktore ugarien arabera. Testua aldizkarian ohikoak diren gaietatik kanpokoa ez bada behintzat, idatziak baztertu egin direla adierazteko jakinarazpenarekin batera, berrikusleen txosten negatiboak eta editore gonbidatuaren iritzia ere igortzen dizkiegu egileei eta haiek, askotan, ez dira agiri horietan adierazitakoarekin ados egoten.

Erabilitako berrikusketa-sistema, beste behin, itsu bikunekoa izan da. Horren bidez, egileek ezin dute jakin zein den berrikusleen nortasuna eta berrikusleek ere ezin dute jakin zein den ebaluatutako idatzien egileen nortasuna. Hala, testuak, banan-banan, editatu egin behar izan dira ebaluatzaile izango zirenek egileen arrastorik ikus ez zezaten: egileen erreferentziak, bidaltze-markak testuan ("Autoaipua" hitza jarri dugu horrelakoen ordez), esker onak eta aipu bibliografikoak. Eragile guztiei (gonbidatutako editoreak, kanpoko berrikusleak eta egileak) eman zaie idatzizko informazioa garatu beharreko ebaluazio-mekanismoen inguruan. Gainera, prozesuaren fase bakoitzerako jarraibide zehatzak jaso dituzte, ebaluatzaileen argibideen inguruko gutxi gorabeherako txantiloia barne. Eragile guztien arteko harremanak bide elektronikoaren bidez egin dira, nahiz eta egile bakoitzak bere jatorrizko dokumentuaren hartu-agiria sinatu duen artikulu bakoitzaren goiburuan data kontsignatuta eta hemen zehaztutako protokoloa onartuta.

Artikuluei DOI kodeak jarrita hobetu egiten zaie sareko ikusgarritasuna. Asko ari da hobetzen; hala erakutsi digute Google Akademikoa (Google Scholars) delakoaren kontrol-erregistroek. 1991. urtetik testu hau idatzi dugun unera arte (2020ko abenduak 29), Munibe Antropologia-Arkeologia aldizkariko artikuluak (1983. urtetik) 6931 aldiz aipatu dira (iaz 6078 aldiz) eta horietatik 2401 azken sei urteetan (2323 duela urtebete). 2016-2020 aldian argitaratutako artikuluak (94 artikulu) dagoeneko 310 aldiz aipatu dituzte; horrek aldizkariaren inpaktu-faktorea eskaintzen digu, eta hauxe da: azken bost urteotan (2021a alde batera utzita), aipa daitekeen artikulu bakoitzeko 3,3 aipu. Urtearen arabera, 2016an argitaratutako artikuluek 128 aipamen izan dituzte; 2017 an argitaratutakoek 75; 2018koek 73; 2019koek 25; eta 2020koek bederatzi baino ez. Aldizkariaren profilean edozein egilek kontsulta dezake Google Akademikoa aplikazioan bere artikulua zenbat aldiz eta zer testuingurutan aipatu izan duten.

Aipatu dugun aldi horretan gehien aipatu izan den artikulua (hogeita bat aldiz), 2016an A. Soto, A. Alday, X. Mangado eta L. Montes egileek argitaratutakoa izan da: "Epipaleolítico y Mesolítico en la vertiente sur de los Pirineos desde la perspectiva de la industria lítica". Gainera, kontuan hartutako urte guztien artean (1983-2020), F. Etxeberriak 1994an argitaratutako artikulua da kanpoko aipamen gehien jaso dituena, hain zuzen ere 101; honakoa da artikulua: "Aspectos macroscópicos del hueso sometido al fuego. Revisión de las cremaciones descritas en el País Vasco desde la Arqueología".

Alvaro Arrizabalaga. Editore nagusia

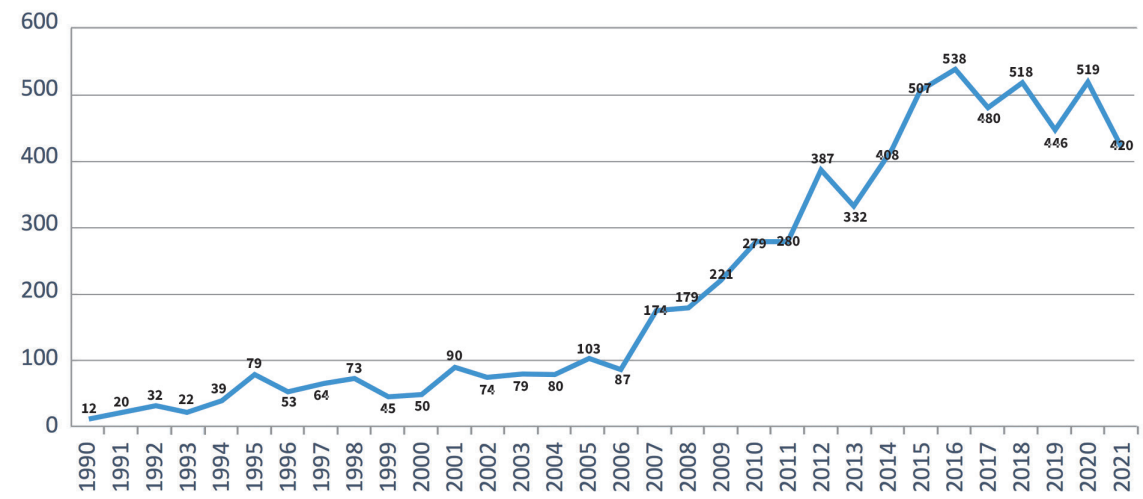

Munibe AA aldizkariaren inguruko aipuak baliabide akademiko ugaritan urte bakoitzean 


\section{Crónica de la revista Munibe Antropologia-Arkeologia 2021}

A lo largo de este año 2021, no hemos procedido a ningún cambio en el proceso de edición de la revista, aunque sí han sido aplicados los anteriores, ya efectivos en 2020: el número máximo de palabras por artículo es de 7.500 (aunque hemos excluido de este cómputo el resumen extendido en inglés) y con 6 figuras como máximo, salvo excepciones justifidas, que serán valoradas por el Comité Editorial de forma individualizada. Tanto el texto, como las figuras, vídeos o información complementaria que no pueda incluirse en esta extensión, podrán ser redirigidos a vínculos online (Suplementary Information), para así poder reducir el número de páginas de cada artículo y poder dar cabida a más originales.

A lo largo de 2021 se han depositado en la redacción de la revista veintisiete originales para su consideración, que se suman a los tres no valorados en 2020. No hemos podido evaluar a tiempo tres originales, que quedan para su consideración a lo largo de 2022. Así pues, el total de manuscritos valorados para este número en papel es de veintisiete. A excepción de las dos recensiones incluidas en este número (que no incluiremos en el cómputo global), cada uno de los originales ha recibido un mínimo de dos revisiones externas, incorporándose en algunos casos una tercera opinión, o alternativamente, la del editor invitado del artículo. Nueve de ellos han sido rechazados por diferentes motivos. Los dieciséis artículos restantes editados en este número, se dividen entre los que han requerido cambios mayores (siete), los que ha bastado con cambios menores (ocho) y uno más que ha sido aceptado en su estado original. En definitiva, sobre veinticinco originales con una evaluación completa, el índice de rechazo de este año representa el 36\%, algo más de un tercio.

El periodo medio entre la recepción del acuso de recibo firmado por el autor de correspondencia y la decisión final acerca de la publicación o no del artículo se ha situado este año, nuevamente excepcional por la pandemia por COVID-19, en diecinueve semanas, aunque resulta muy variable en función a distintos factores como la longitud o temática del artículo. Salvo alineamiento del manuscrito fuera de las temáticas habituales de la revista, los rechazos van acompañados de los informes negativos de los revisores y la opinión del propio editor invitado del mismo, documentos con los que los autores van a discrepar de modo habitual.

El sistema de revisión empleado ha sido nuevamente el de doble ciego, lo que impide, tanto a los autores conocer la identi- dad de los revisores, como a estos, conocer la de los autores de los manuscritos evaluados. Esto ha obligado a editar cada manuscrito para eliminar cualquier rastro del / de los autores a los eventuales evaluadores: referencias de los autores, llama- das en el texto (sustituidas por la expresión "Autocita", para no romper el discurso), agradecimientos y citas bibliográficas. Todos los agentes (editores invitados, revisores externos y autores) han sido puntualmente informados por escrito de los mecanismos de evaluación que se iban a desarrollar y han dispuesto de instrucciones precisas para cada fase del proceso, incluyendo una plantilla orientativa de indicaciones de los evaluadores. Las relaciones entre todos los agentes se han efectuado por la vía electrónica, aunque cada autor ha firmado un acuse de recibo de su original, con la fecha consignada en la cabecera de cada artículo, aceptando el protocolo aquí detallado.

La dotación de códigos DOI a los artículos viene incrementando su visibilidad en la red, que va mejorando sustancialmente tal y como observamos en los registros de control de Google Académico. Desde el año 1991, hasta la redacción de este texto (29 de diciembre de 2020), los diferentes artículos de Munibe Antropologia-Arkeologia (desde 1983) han sido citados 6931 veces (frente a 6078 veces, el año pasado), 2401 de las cuales durante los últimos seis años (por 2323 hace un año). Los artículos publicados durante el periodo 2016-2020 (94 artículos) han sido citados ya 310 veces, lo que nos proporciona el factor de impacto de la revista, para los últimos cinco años (descontado 2021), de 3,3 citas por artículo citable. Atendiendo a su anualización, los artículos publicados en 2016 acumulan 128 citas; los de 2017, 75 citas; los de 2018, 73 citas; los de 2019, 25 citas; los de 2020, solo nueve citas. Cualquier autor puede consultar en el perfil de la revista en Google Académico el número de veces que su artículo ha sido citado y en qué contexto lo ha sido.

Para el periodo reciente citado, el artículo más citado (en veintiuna ocasiones) ha sido el publicado en 2016 por A. Soto, A. Alday, X. Mangado y L. Montes: "Epipaleolítico y Mesolítico en la vertiente sur de los Pirineos desde la perspectiva de la industria lítica". Además, para el conjunto de años medidos (1983-2020), el artículo de F. Etxeberria publicado en 1994, "Aspectos macroscópicos del hueso sometido al fuego. Revisión de las cremaciones descritas en el País Vasco desde la Arqueología", con 101 citas, acumula el mayor número de citas externas.

Alvaro Arrizabalaga. Editor Principal

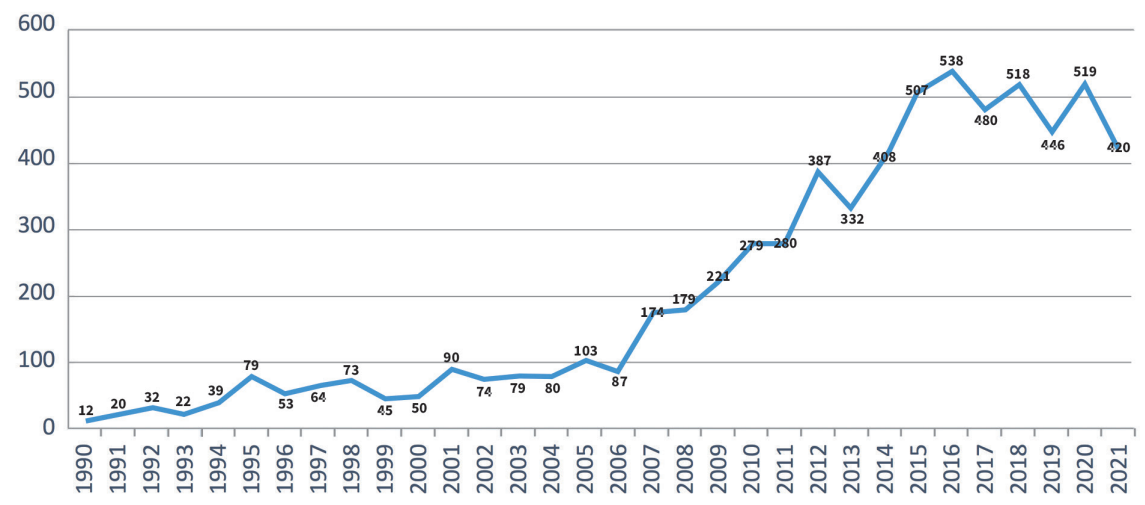

Citas a la revista Munibe AA en distintos medios académicos por año. 